\title{
Initial trimming followed by complete removal of an esophageal self-expandable metal stent for stent-related symptoms
}

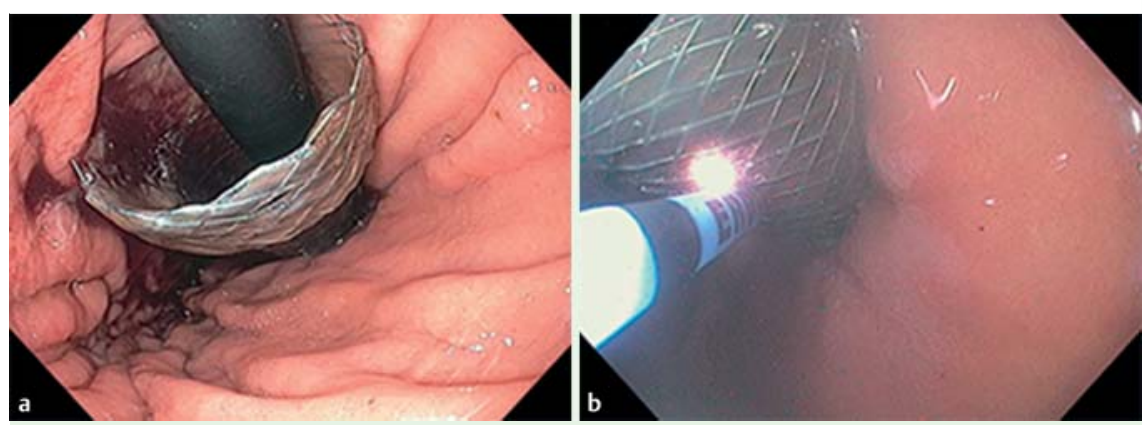

Fig. 1 Endoscopic images showing: a the esophageal covered metal stent with its distal edge protruding into the stomach wall (retrograde view); $\mathbf{b}$ the esophageal covered metal stent being trimmed using argon plasma coagulation in retroflexed view.

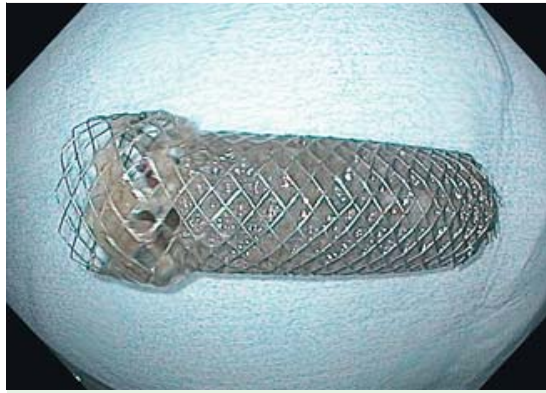

Fig. 2 The transected portion of the covered metal stent.

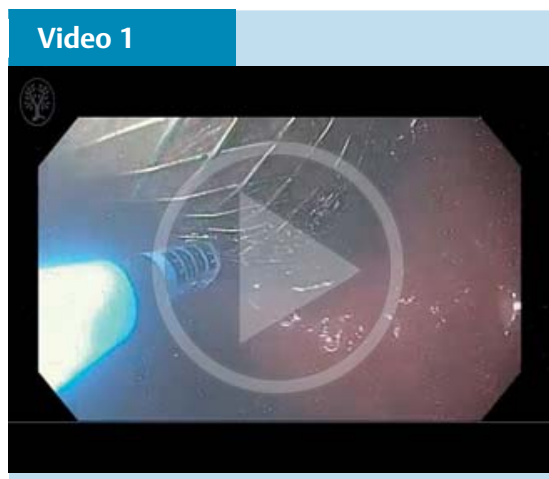

Endoscopic trimming of the esophageal covered metal stent using argon plasma coagulation: the esophageal covered metal stent is seen protruding into the stomach wall; the distal part of the stent is trimmed using argon plasma coagulation in retroflexed view; the transected stent is removed using a snare.

Placement of long, protruding self-expandable metal stents (SEMSs) into the gastrointestinal lumen may cause related symptoms. A few reports have described the usefulness of argon plasma coagulation (APC) for trimming or fenestrating a

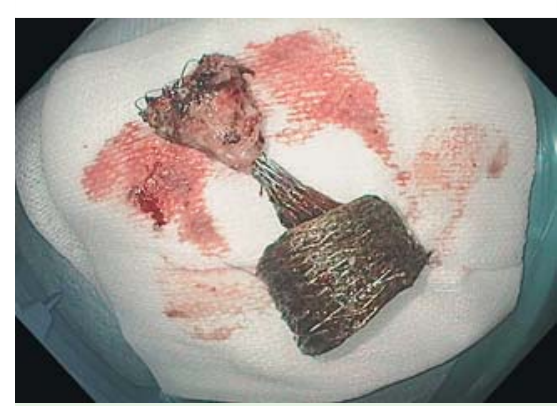

Fig. 3 The remainder of the covered metal stent following its complete removal 3 months later.

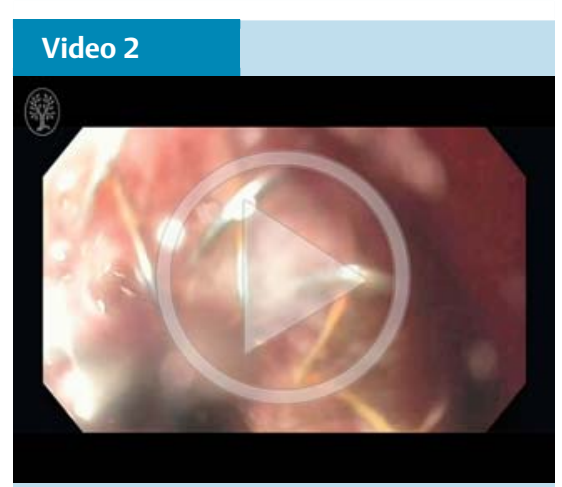

Endoscopic removal of the esophageal covered metal stent: the distal part of the stent is grabbed with a rat-toothed forceps, and the stent is removed completely using an inversion technique by rotating and withdrawing the endoscope.

SEMS [1 -4]. We report a trimming technique for a covered SEMS in the esophagus using APC in a retrograde fashion, followed by its complete removal.

A 67-year-old woman presented with dysphagia. Esophagogastroduodenoscopy

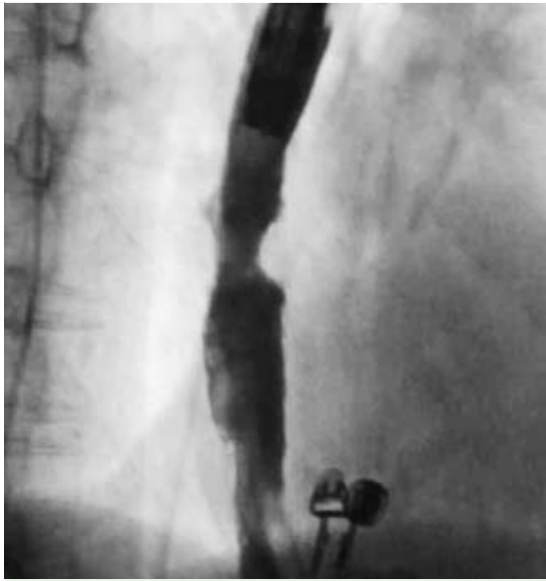

Fig. 4 Esophagogram showing a patent esophagus with no extravasation of contrast.

(EGD) showed a large ulcerated tumor in the esophagus with tumor excavation. A 12-cm partially covered SEMS was placed across the tumor. Subsequently the patient was able to resume eating solid food and underwent chemotherapy. However, 1 month after stent placement, she developed epigastric pain and dysphagia from impaction of the stent into the proximal stomach ( Fig. 1 a). The distal portion of the stent was trimmed with APC using a generator at a setting of $80 \mathrm{~W}$ and a flow rate of $2 \mathrm{~L} / \mathrm{min}$ ( Fig. $1 \mathbf{b}$; $\bullet$ Video 1 ). The procedure was performed with the scope in a retroflexed position to prevent esophageal mucosal injury. A length of the stent (approximately $4 \mathrm{~cm}$ ) was completely severed in a circumferential manner and was successfully removed from the stomach ( $\bullet$ Fig. 2). After the procedure, the patient's pain and dysphagia improved.

After 3 months, however, she developed severe acid reflux and we decided to remove the remainder of the stent. Hyperplastic tissue at the uncovered proximal part of the stent was leveled using a stiff snare and APC to free up some of the mesh from the mucosa. The distal part of the stent was then grabbed with a rattoothed forceps, and the endoscope was withdrawn in a steady rotational fashion, such that the mesh eventually inverted, was dislodged, and then was successfully removed en bloc ( $\bullet$ Fig. 3; $\bullet$ Video 2 ). A subsequent esophagogram demonstrated 
improvement of the stricture without evidence of contrast extravasation ( $\bullet$ Fig.4). All of the patient's stent-related symptoms resolved after these interventions.

Endoscopy_UCTN_Code_TTT_1AO_2AZ

Competing interests: None

Takeshi Tsujino, John G. Lee, Kenneth J. Chang

Division of Gastroenterology and Hepatology, H.H. Chao Comprehensive Digestive Disease Center, University of California, Orange, California, USA

\section{References}

1 Rerknimitr R, Naprasert P, Kongkam $P$ et al. Trimming a metallic biliary stent using an argon plasma coagulator. Cardiovasc Intervent Radiol 2007; 30: 534-536

2 Ishii $K$, Itoi T, Sofuni A et al. Endoscopic removal and trimming of distal self-expandable metallic biliary stents. World J Gastroenterol 2011; 17: $2652-2657$

3 Hamada T, Nakai $Y$, Isayama $H$ et al. Trimming a covered metal stent during hepaticogastrostomy by using argon plasma coagulation. Gastrointest Endosc 2013; 78: 817

4 Tieu AH, Saxena P, Singh VK et al. Fenestration of a covered metal stent during cystoduodenostomy using argon plasma coagulation. Endoscopy 2014; 46 (Suppl. 01): E512-E513

\section{Bibliography}

DOI http://dx.doi.org/

10.1055/s-0042-102881

Endoscopy 2016; 48: E109-E110

(c) Georg Thieme Verlag KG

Stuttgart · New York

ISSN 0013-726X

\section{Corresponding author}

\section{Kenneth J. Chang, MD}

H.H. Chao Comprehensive Digestive Disease Center, University of California Irvine Medical Center

101 The City Drive. Bldg. 22C

Orange

CA 92868

USA

Fax: +1-714-456-7520

kchang@uci.edu 